\title{
Multiple strategies for relaxation techniques to manage attrition or dropout in reducing Generalized Anxiety Disorder (GAD) symptoms: A case study of Indonesian Homemaker
}

Faiz Agung Baskoro ${ }^{\mathrm{a}}$ and Lathifah Hanum ${ }^{\mathrm{b}}$

${ }^{a}$ Faculty of Psychology, Universitas Indonesia, Depok, Indonesia; ${ }^{b}$ Department of Clinical Psychology, Faculty of Psychology, Universitas Indonesia, Depok, Indonesia;

*Corresponding author:

Lathifah Hanum

Department of Clinical Psychology

Faculty of Psychology, Universitas Indonesia

Jl. Lkr. Kampus Raya, Depok, Jawa Barat

Indonesia, 16424

Tel.: +62 217270004

Email address: lathifah.hanum@ui.ac.id / lathifah.hanum@gmail.com 


\title{
Multiple strategies for relaxation techniques to manage attrition or dropout in reducing Generalized Anxiety Disorder (GAD) symptoms: A case study of Indonesian Homemaker
}

\begin{abstract}
Similar to other anxiety disorders, reducing the intensity and the emersion of generalized anxiety disorder (GAD) symptoms of the client is somewhat necessary before managing the primary resource of the disorder. However, an undeniable circumstance is that the client experienced a stuck point where they felt that the intervention was too difficult to implement or irrelevant to their current problem. This condition usually leads to attrition/dropout that interfere with the progress of therapy sessions. Such a typical situation frequently occurred in Indonesian clients in the public medical service, and specifically in a client in a community health center, who was an Indonesia homemaker. There was a common misconception from the client that any treatment should lead to instant remedy, and could be implemented efficiently in her current routine. Moreover, the client's involvement in therapy was usually based on her enthusiasm, comfort, and feelings of ease, and behavioral changes were observed in every session. One of the reasonable solutions to this problem is to encourage the client to use multiple strategies that share the main principles of intervention, in this case, using various relaxation techniques to reduce anxiety symptoms. With alternative resources, the clients could choose the method that fits best in their particular routine without diminishing its impact on the client's symptoms. This research aimed to illustrate the dynamic process of GAD-symptoms intervention in a patient of the community medical service in Indonesia (Puskesmas), using two types of relaxation techniques, progressive relaxation, and deep-breathing orientation. The subject of this study was an outpatient fulltime homemaker from a middle class family who received a diagnosis of GAD from a psychologist and never sought professional treatment for her disorder. She held a common misconception about psychotherapy based on the interview prior therapy. Using the case study method, one participant was involved in this research. The subjective experience of the client and her behaviors related to anxiety here described and analyzed in chronological order based on the days within therapy sessions (the approximate duration of each session was 2 hours). The data was collected over 3 months of therapy sessions by using interview and observation as primary instruments. The result showed that the client felt more enthusiastic and helped with the alternative solution provided. She could choose the most comfortable technique that felt more compatible with her current routines, such as deep-breathing orientation when she had a tight schedule and progressive relaxation in opposite situations. She also felt more enthusiastic when she could share and teach her peers about the implemented relaxation techniques in her routine because of the simplicity and ease. There was also consistent reduction of the symptoms reported compared with the baseline and after the intervention using either progressive relaxation or deep-breathing orientation based on the client's daily selfmonitoring and researcher observation in the face-to-face sessions. These results provide a single clue that leads to the evidence of multiple relaxation strategies to overcome dropout/attrition in GAD clients. Furthermore, there was a slight contribution to provide the practical framework for research and intervention when managing an Indonesian client experiencing GAD and a stuck point during the intervention.
\end{abstract}


Keywords - anxiety symptom, attrition, dropout, multiple strategy intervention, relaxation

\section{Introduction}

Cognitive behavior-based therapy (CBT) became one of the most popular and scientifically proven interventions for generalized anxiety disorder (GAD) and other anxiety disorders (Antony, 2011). Several researchers have indicated that CBT could significantly reduce the symptoms of these type of disorders. The result from randomized clinical trial (RCT) research has demonstrated the significant difference in symptoms reported between the experiment and the control group (Hayes-Skelton, Roemer, \& Orsillo, 2013). Fewer symptoms were reported in the group with CBT than in the control group. This result was consistent with meta-analysis study of the effectivity of several psychotherapy techniques (e.g., CBT, relaxation, and integrated psychotherapy) on reducing symptoms of anxiety disorders including GAD (Goncalves \& Byrne, 2012; Hall, Kellet, Berrios, Bains, \& Scott, 2016; Hans \& Hiller, 2013). In addition to its effectivity, CBT compared with other techniques shows slightly higher means of symptom reduction in anxiety disorder.

Although the robustness in effectivity has been demonstrated, CBT has a notable limitation regarding its efficiency. This therapy has been demonstrated to have a higher risk of attrition/dropout compared with the other therapies (Hans \& Hiller, 2013; Issakidis \& Andrews, 2004; Swift \& Greenberg, 2014). There is no standard definition for attrition or dropout, and both concepts share the same pattern in many situations (Issakidis \& Andrews, 2004). Therefore, it is not surprising that some research does not categorize these concepts as separate variables to measure (Hans \& Hiller, 2013; Swift \& Greenberg, 2014). A safe assertion is that attrition/dropout is the condition when the clients slack off from the meeting and terminate the therapy process without any discussion with the therapist (Hans \& Hiller, 2013; Issakidis \& Andrews, 2004; Swift \& Greenberg, 2014). Attrition/dropout could have a negative impact on the client or the therapist. Dissatisfaction with therapy highly associated with attrition/dropout from therapy could lead to decreasing the client's overall well-being. For a therapist, experiencing attrition/dropout of a client could make them ruminate over guilty feelings or feel ashamed (Swift \& Greenberg, 2014). For the case of anxiety disorder, attrition due to exposure in the CBT could be the indication of heightened anxiety (Issakidis \& Andrews, 2004).

Research on attrition/dropout in psychotherapy especially in anxiety disorder cases has shown that client therapist interaction process has a more prominent contribution than sociodemographic factors to reduce attrition/dropout from therapy (Fenger, Mortensen, Poulsen, \& Lau, 2010; Issakidis \& Andrews, 2004; Roos \& Werbart, 2013). One of the main factors that contributes to this process is client's expectation of therapy (Fenger, Mortensen, Poulsen, \& Lau, 2010; Roos \& Werbart, 2013; Swift \& Greenberg, 2014). Therapies that fulfill a client's expectations regarding easiness and flexibility could lead to lower attrition/dropout than other therapies. Clients might be more likely to reject or terminate the therapy prematurely when they perceive that the therapy procedure burdens their life because of its complexity and rigidity regarding the procedure. Compared with another technique such as integrated psychotherapy, 
CBT presented more complicated and standardized procedures that apparently were more effortful for client to comprehend and apply (Fenger, Mortensen, Poulsen \& Lau, 2010). Therefore, providing clients with simpler, more adjustable treatments with equal effectivity to CBT could be a promising solution to overcome the attrition/dropout problem.

The aforementioned situation has resulted in the attention of many clinicians and scholars to the other form of therapy that has the same efficacy as CBT but is simpler and more flexible in the procedural aspect (more practical and adjustable to client's preferences) (Goncalves \& Byrne, 2012; Siey \& Chambless, 2008), such as applied relaxation. Supported by a rigorous and systematic study on its effectivity for GAD (Donegan \& Dugas, 2012; Hayes-Skelton, Roemer, \& Orsillo, 2013), applied relaxation has a relatively simple procedure because it is straightforward and easy to learn for the client. Because there were bidirectional influences between somatic symptoms (e.g., muscular tension) and psychological symptoms (e.g., worry), applied relaxation that focused on reducing somatic symptoms could also make a general improvement in a client's condition regarding the overall symptoms without sacrificing its simplicity (Donegan \& Dugas, 2012). Additionally, the flexibility demand for this therapy could be fulfilled by relying on the principle of applied relaxation practice. Applied relaxation has various form of techniques that shared the main purpose and principles (Donegan \& Dugas, 2012; Goncalves \& Byrne, 2012; Hayes-Skelton, Roemer, \& Orsillo, 2013). Notably, a single type of applied relaxation program that contains many forms of techniques that could be substituted for one another (e.g., an intervention program with diaphragmatic breathing and progressive relaxation) is not unsual (Hayes-Skelton, Roemer, \& Orsillo, 2013; Roos \& Werbart, 2013; Siey \& Chambless, 2008). One of the main purposes of this particular arrangement is the multiple dimensional nature of relaxation (Bernstein, Borkovec, \& HazlettStevens, 2000; Siey \& Chambless, 2008). In other words, multiple methods have been used to induce relaxation. This condition results in applied relaxation possessing relatively high flexibility regarding adjustments to client preferences because its nature is to be set in a multiple strategy arrangement. It is also probably one possible explanation behind the relatively low dropout/attrition in the applied relaxation treatment including for GAD (Hayes-Skelton, Roemer, \& Orsillo, 2013; Siey \& Chambless, 2008).

Regardless of the plausibility of the multitude of alternative relaxation techniques, no solid and comprehensive practical framework for implementation of multiple strategy relaxation to manage attrition/dropout in GAD client has been presented. Although this strategy is used frequently within the applied relaxation treatment for GAD and has received scientific support regarding its lower dropout/attrition than another treatment (Hayes-Skelton, Roemer, \& Orsillo, 2013; Siey \& Chambless, 2008), it was not specifically and directly targeting the dropout/attrition of clients. And rarely was there any further discussion about the implementation process of this particular strategy to reduce dropout/attrition in the studies of GAD intervention. This gap could be one of the primary obstacles to implementing such a strategy in clinical practice because providing a plausible explanation is one of the fundamental function of clinical study (Comer \& Comer, 2018; Trull \& Prinstein, 2013). Therefore, any effort to provide the theoretical explanation to fulfill this gap has value because of the urgency. 
One of the best ways to illustrate the strategical process is to observe the implementation of multiple strategies of relaxation in a community health service client in Indonesia. Indonesian Community Health Services (Pusat Kesehatan Masyarakat/Puskesmas) has a high rate of client attrition and dropout in therapy (Universitas Indonesia, 2018; 2018). More than $50 \%$ of the clients in Puskesmas did not show on the second meeting. Approximately $80 \%$ of participants didn't attend the fifth or sixth session and never made contact to cancel the appointment. This condition apparently presents in outpatient community health care in general (Hans \& Hiller, 2013). The occurrence of this phenomenon is associated with the client's common misconception about psychotherapy. First, clients think that any type of medication should lead to an instant remedy. Second, clients think that any type of therapy must be easy to apply (no need for repetition/practice and no homework). Third, clients expect direct guidance rather than facilitated insights (Universitas Indonesia, 2018). In reality, psychotherapies consume more time than clients expect, take some effort to learn, and facilitate self-healing rather than prescribe healing techniques (Seligman, 2015). Thus, this conflict is naturally the source of attrition/dropout. By contrast, a client with signs of an anxiety problem that receive applied relaxation treatment (e.g., progressive relaxation or deep-breathing orientation) is less likely to drop out from therapy before the next meeting (Universitas Indonesia, 2018; 2018). Some clients that discuss their practical problems regarding the implementation of the earlier relaxation technique (e.g., report the procedure is time-consuming considering their unexpected tight schedule) and receive an additional relaxation technique that is more compatible for their situation are less likely to be absent/no show/dropout from the fifth to the sixth session. By contrast, the somatic symptom focused treatment in a relaxation technique could favor this therapy to reduce the possibility of attrition/dropout because Asian people prioritize somatic symptoms over psychological symptoms (Ryder et al., 2008; Arnault \& Woo, 2018).

Therefore, the main purpose of this research was to assess the dynamic process of a GAD symptom intervention in a client in Puskesmas using two types of relaxation techniques, progressive relaxation, and deep-breathing orientation. This research aimed to assess how the multiple strategies for relaxation influence a client's experience and decision regarding therapy. Specifically, this study, we aimed to illustrate the implementation of multiple strategies for relaxation that affect client's decision to continue the therapy program.

\section{Methods}

\section{Research method}

This research used a clinical case study as the method to fulfill the research purposes (Christensen, Johnson, \& Turner, 2015). This method was established to illustrate the process within some sort of phenomenon and navigate the dynamic interaction between any variable that was observed within the phenomenon (Lowman \& Kilburg, 2011). Thus, this method facilitates the description and explanation regarding the influence of the interaction between multiple strategies for relaxation, attrition/dropout, and GAD symptoms. 


\section{Participant}

The participant was a 50-year-old female homemaker who voluntarily attended the facility without any referral from physicians or insistence from her family. Prior to the treatment, the client was already aware of the relation between her somatic compliant and her psychological states and unaware of any possibility of receiving a mental disorder diagnosis. She was diagnosed with GAD by a licensed psychologist and had a clean medical record. She participated in nine therapy sessions (over 3 months) with approximately 6 days' interval between sessions (once per week). The duration of a session was approximately 2 hours. The government covered all her treatment costs. Her participation rate passed the minimum criteria for non-attrition/non-dropout from therapy (Swift \& Greenberg, 2014). The client completed the full procedure of progressive relaxation and deep-breathing orientation. She had many misconceptions about psychotherapy as aforementioned (see Introduction).

The client was a fulltime housewife of a middle class economy family. She was responsible for performing all the household duties by herself, including managing the family's finances (e.g., budgeting the salary earned by her husband, and all the family's expenditure). She valued the traditional Javanese lifestyle. As a personal preference, she liked to interact with people (her friends and family) and to contribute to any activity that served the collective interest. She believed that her source of happiness was acknowledgement from people (especially from her family and friends) for her contribution to their well-being. She felt intense grief after her last child left home to pursue higher education outside the province. Additionally, she and her husband often fought because of their financial problems.

\section{Relaxation Techniques}

Progressive relaxation - This research implemented progressive relaxation procedure developed by Soeswondo, Menaldi, and Hanum (2016). The therapist asked the client to tense the muscles in a certain area of her body until she reached her limit (the limit was perceived and judged by the therapist). This intervention was carried out by a graduate student trained in progressive relaxation in a clinical psychology program and supervised by a licensed psychologist. Afterward, the client asked to relax her muscles and release the tension from her body. Next, the therapist persuaded her to feel the difference between the experience and sensation in her tensed body and her relaxed body. This process was repeated nine times in nine different areas of the client's body (e.g., right arm, left arm, right leg, left leg, forehead, eyes, jaw, chest, rear, and neck). At the beginning of the therapy, the client was asked to implement the technique in all muscular areas of her body or implement full progressive relaxation (Full PR). Later on, the client could use short progressive relaxation (Short PR), which she used for only three areas that significantly relaxing or the area that became the source of a muscular complaint (in her case: right leg, chest, and neck). The Full PR had a more powerful impact than the Short PR because it relaxed the bigger muscular areas, but consumed more time and was more complicated than the Short PR. Because the significant change was the main priority for the client in the early stage of the therapy, Full PR was implemented prior to the other form of relaxation. When the client felt less anxious, report fewer somatic complaint, and started to increase her daily activity, Short PR with more efficient procedure 
than Full PR was introduced to the client. The client was asked to do perform the technique once per day.

Deep Breathing - The implementation of the deep breathing relaxation procedure was developed by the team of psychotraumatology trainers for Pelatihan Psikotraumatologi, Stabilisasi Emosi dan Resource Development and Installation in Universitas Indonesia (2017) and was used in this research. This intervention was also carried out by a graduate student trained in progressive relaxation in a clinical psychology program and supervised by a licensed psychologist. Essentially, the therapist taught the client to breathe with her diaphragm slowly and consistently. While at the anxious level, an individual usually breathes faster and shorter using his/her chest. By contrast, a relaxed person breathes more slowly and deeply using his/her diaphragm. Therefore, by altering the breathing mechanism from using chest to using the diaphragm, anxious people would become more relaxed and calm. First, the client was asked by the therapist to count her breathing rate in one minute. Second, the client was asked to breathe slower than before using by her diaphragm. In this stage, therapist instructed the client to take a deep breath, hold it in for 3 seconds, exhale the breath slowly through her mouth for 8 seconds, and hold the breath for 3 seconds before repeating the process until the client looks calmer. This technique compared with the Full or Short PR was simpler, consumed relatively little time, and was less power full. Deep breathing was introduced to the client after Full and Short PR. The client was asked to perform this breathing technique every day.

\section{Procedure}

Measuring the client's general anxiety level - This research used interview and observation as the main instrument for data collection. This research also used a personal anxiety scale to assess the gradation of anxiousness inside the participant's subjective experience to indicate the change in anxiety level. The researcher asked the participant to identify her current anxiety level by stating one number listed on the scale $(1=$ very calm/relaxed to $10=$ very worried/uneasy). To assess the general change in anxiety level, these measurements assessed before the session started. The researcher conducted an interview about the client's general thoughts, feelings, and bodily concerns during that time. The client's anxiety-related behavior was recorded by the therapist during the session. Afterward, client anxiousness was measured using a personal anxiety scale and clarified through an inquiry interview.

Measuring the client's daily anxiety level - To assess how relaxation techniques (each one of them or the whole) influence client anxiety in daily life, the participant was asked to selfmonitor regarding her anxiety level before and after relaxation every day using a personal anxiety scale. In every session, the participant was asked to report her self-monitoring result to the researcher before the session started.

Describing the client's personal experience toward multiple relaxation strategies - The researcher conducted an interview after the session when the participant learned one of the three relaxation techniques from the therapist. This interview mainly focused on the participant's thoughts and feelings regarding the strategical change/improvement. In particular, 
the client's personal thoughts and feelings after mastering multiple relaxation strategies: (1) Full PR, (2) Full PR \& Short PR, and (3) Full PR \& Short PR \& Deep breathing.

TABLE. 1 Clinical Report of All the Client's Sessions

\begin{tabular}{|l|l|l|l|l|l|}
\hline & Session I & Session II & Session III & $\begin{array}{l}\text { Session } \\
\text { IV }\end{array}$ & $\begin{array}{l}\text { Session } \\
\text { V }\end{array}$ \\
\hline Anxiety-level & $\mathbf{8}$ & $\mathbf{6}$ & $\mathbf{6}$ & $\mathbf{4}$ & $\mathbf{4}$ \\
\hline $\begin{array}{l}\text { Anxiety- } \\
\text { related } \\
\text { behavior }\end{array}$ & $\begin{array}{l}\text { Rapid eye } \\
\text { blink, face } \\
\text { sweating \& } \\
\text { short } \\
\text { breathing, }\end{array}$ & $\begin{array}{l}\text { Rapid eye } \\
\text { blink, face } \\
\text { sweating \& } \\
\text { short } \\
\text { breathing, }\end{array}$ & $\begin{array}{l}\text { Rapid eye } \\
\text { blink, short } \\
\text { and fast } \\
\text { breathing, }\end{array}$ & $\begin{array}{l}\text { Rapid } \\
\text { eye blink }\end{array}$ & \\
\hline $\begin{array}{l}\text { Complaint of } \\
\text { muscular pain }\end{array}$ & $\begin{array}{l}\text { Left chest, } \\
\text { behind the } \\
\text { neck, and } \\
\text { right leg }\end{array}$ & $\begin{array}{l}\text { Left chest, } \\
\text { behind the } \\
\text { neck, and } \\
\text { right leg }\end{array}$ & $\begin{array}{l}\text { Behind the } \\
\text { neck }\end{array}$ & & \\
\hline
\end{tabular}

\section{Result}

\section{Client's Perception Regarding Treatment Effectivity}

A slight reduction was observed in the number of the anxiety level from the earlier to the later sessions. The number decreased from eight to four, which means the client felt less anxious in the later sessions than in the earlier sessions. This substantial reduction was followed by a decrease in the amount of anxiety-related behavior in the later sessions. Furthermore, the client did not show any anxiety-related behavior in the fifth sessions. Regarding the client's complaint of muscular pain, a substantial difference was observed in the client's report each session. The client reported fewer complaints in the third and fifth session. She also reported no complaints in the fifth session and felt much better (e.g., calmer and motivated) compared with the earlier sessions. All of the aforementioned conditions were perceived by the client as signs of effective treatment, although she did not put all of it in equal manner consistently.

At the beginning of the therapy (sessions I and II), the participant perceived the muscular compliant as the true problem or the source of disturbance in her life. Thus, she believed that the treatment was effective when she felt less pain after finishing any relaxation procedure. In other words, her perception of treatment effectivity tended to be based on her personal satisfaction regarding how the treatment could overcome her top priority problem (the physical problem). This particular condition was probably influenced by her cultural background. In the concept of help-seeking behavior, Asian people tolerate more severe physical symptoms compared with psychological. Asian people tend to consider the physical symptoms as the only reasonable excuse to seek help (Arnault \& Woo, 2018; Ryder et al., 2008). Therefore, it was not surprising that the participant tended to focus more on the physical complaint in the early stage of the sessions. Full PR became a powerful technique for the participant because she could feel a contrast in bodily sensation between the tense state and the relaxed state. In the later stage (sessions III to IV), the client started to have more concerns on related to the practical aspects 
of the techniques after experiencing less muscular pain. She felt more capable to take over all her responsibilities at home again. In this stage, she said that full progressive relaxation was becoming a bit too much for her (necessary when things got worse but too excessive for her current situation) because it was time-consuming. She felt it was less of a struggle to enter the relaxed state now. Her central role in the family and her husband's middle-class income that prevented her from hiring someone to take responsibility for her housework forced her to take hurried steps toward her healing process. She did not want to waste too much time on her personal growth because she had bonded with other people's expectations. A simpler technique such as Short PR and Deep breathing became her preferred techniques. Additionally, the client's enthusiasm increased when she knew that the later technique could produce the exact same experience as the earlier technique. This experience increased the client certainty about the effectivity of the whole therapy program.

The client's self-monitoring reports about her daily anxiety also show a slight difference in the personal anxiety scale mean score before and after the daily relaxation practice. All three types of relaxation show relatively difference before and after the treatment. The mean score of posttreatment anxiety level was lower than pretreatment anxiety level for all the types of techniques. She said that she recognized the association between her mind and her bodily sensation after performing the procedure repeatedly (the procedure push the client to observe herself in a broader sense: mind, feeling, and body). These conditions were perceived by the client as a sign of the equal effectivity of each of the techniques and a sign of the effectivity of multiple strategies. She thought that all the techniques somehow related to one another and were equally effective.

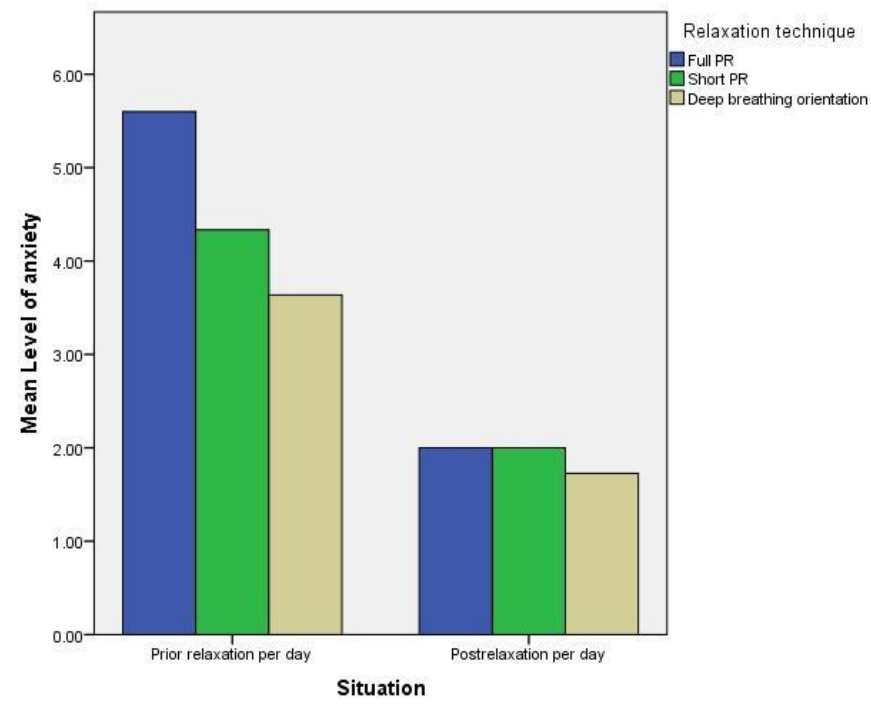

Fig. 1. Client Daily Anxiety Level

In the fifth stage, the client felt more confidence in overcoming her physical reaction to anxiety; she thought that she was more equipped to manage it. The client then started to focus on the source problem of her anxiety (e.g., her irrational thought and her relationship concerns) rather than on her physical symptoms. She felt that she could attain more in this therapy program and might missed something precious if she terminates the treatment. 


\section{Client's Phenomenological Pathways}

At least three pathways explain the client's decision to attend the next sessions. The first pathway is as follows: The simplicity and efficacy of relaxation techniques made the client experience heightened feelings such as excitement and enthusiasm. These feelings led to the client feeling positive feeling about the therapy. She felt happy and joyful when thinking about or participating in the therapy. This condition influenced her decisions and increased her likelihood of attending the next meeting. Regardless of the simplicity of the technique, regarding the second pathway, the efficacy of the relaxation technique that is based on significant feeling on the bodily sensation change (reduction of bodily complaints) increased the client's optimism regarding overcoming the disorder. This thought led the client to perceive therapy as useful. Therefore, having this thought increased the possibility of her attending the next meeting. The third pathway stems from the client's thought that the treatment was easy to learn because of its simplicity. The client thought that because the treatment was easy for her to learn that it would also be easy to teach. She could understand that her learning these techniques could benefit others. In this case, the client thought that her teaching this technique to her peers or family, especially when the member of that social group shared the same problem as the client, could benefit both of them. This collective gain paradigm could strengthen the thought of therapy usefulness; later on, it increased the probability of the client attending the next meeting.

Different pathways describe the influence of the client's perception of alternative treatments on her decision to attend the next meeting. This particular thought prevents or decreases the demoted feeling of the client, such as boredom and distress, because of the burden of her therapy. Because she knew that an easier alternative with equal effectiveness has been provided, she became protected from that demoted feeling the led her to not feel negative emotions regarding therapy. It also did not decrease her likeliness to attend the next sessions. The perception of equal alternatives also contributes to preventing the client's pessimism regarding therapy. The existence of equally effective alternatives would maintain the client's hope for a positive recovery. Thus, the perception that an equal alternative was based on multiple strategies for relaxation apparently became the protective factor for the client from attrition/dropout.

\section{Discussion and Conclusion}

The researcher navigated two patterns observed within the process of strategy implementation. First, the pattern of the client's perception of treatment effectivity. The process began with the client agenda to alleviate her problem(s). The client reported her priorities regarding the problem(s) and her expectations regarding whether the therapist could do something about it. In this study, a revelation was that the client's main priority was overcoming her physical symptoms or muscular pain. She expected the therapist to treat her muscle pain and that the result would be less pain after the treatment. This situation was the core purpose of this therapy program because it possibly stemmed from the cultural aspect of help-seeking behavior (Arnault $\&$ Woo, 2018) and tended to exist constantly throughout the therapy. Therefore, reducing the client's physical pain became the primary focus of the therapy, especially in the earlier sessions. The therapist should lead or guide the client to feel the difference between her tensed body and relaxed body. Using the most powerful relaxation (e.g., Full PR) technique, regardless of its 
complexity, would have been helpful for the therapist because the client demanded a quick change (a change in one session). In the later stage, discussing the practicality of implementing the technique in the early stage became one important issue. The client most likely to hurry her healing process after she felt slightly better. Her priority to participate in therapy could subside because of her elevated interest in another activity that had already become her daily routine before the treatment. This was undeniably the situation because she was demanded to do so by her environment (the fulltime homemaker that could not afford to hire a helper and handle all types of housework and a certain type of family business by herself). In this situation, providing her with a simpler technique that was equally impactful as the earlier technique (based on her perception) would maintain the progress achieved in therapy. The main target of this stage was to ensure the client was always connected to the therapy progress (she keep doing her relaxation procedure without compromising too much of her daily agenda).

Second, the pattern of the client's affect toward therapy. The core purpose underlying this process was maintaining the client's positive attitude toward therapy at a relatively high level. In other words, the therapist should somehow match the therapy program with the client's expectations and preferences. After assurance from the positive outcome of the first or earlier session, the client felt a heightened feeling toward therapy, such as excited and enthusiastic. She also became more optimistic regarding her recovery because of the immediate change during the sessions. Another factor that possibly increased the positive feelings was the simplicity of the technique. The client felt that she could teach this technique for the good of others and contribute to other people gain. This way of thinking was probably influenced by her personality (a tendency to seek acknowledgment from others) or the collective nature of Eastern culture (Hofstede, 2011). All these positive factors (factors that increased the client's positive affect) emerged through the influence of the characteristics of applied relaxation (direct, simple, and impactful), and it is likely to occur in the early stage of the therapy program. The effect of multiple strategies could be because in the later stage the client started to discuss the practical issues regarding the relaxation procedure and working with the therapist to seek the most compatible technique for her situation without sacrificing its effectivity. This type of strategy made the client perceive another alternative form of the technique that was equally effective as the earlier technique. It was mainly the client's hope regarding the progress of the therapy that protected the client from despair and pessimism. At this stage, the main purpose of the strategy was reducing the negative factor.

This research also demonstrated two main statements. First, the statement about Asian people's preference to be more concerned about their somatic symptoms compared with psychological symptoms in anxiety disorder, and in particular for GAD. The client decided to keep attending the next meeting because of her opinion that the treatment could reduce her physical complaint (decrease the amount of complaint) and improve her physical well-being. This result is consistent with the research on this particular topic (Arnault \& Woo, 2018; Ryder et al., 2008). In Eastern people, displaying somatic symptoms was more acceptable than displaying psychological symptoms. This preference was shaped by cultural values and norms (Ryder et al., 2008) and, thus, included a cultural predisposition in decision-making toward a client's treatment plan that could lead to positive outcomes in therapy (reduce percentage of client's 
attrition/dropout). Second, the statement about the influence of simpler and more adjustable intervention to manage attrition/dropout in therapy regarding GAD. Applying multiple strategies for relaxation or inducing the equal alternative paradigm to the client probably has an important role as a protective factor from attrition/dropout. Providing clients with easier techniques with the relatively the same effect could maintain the client's hope to get better and overcome his/her problem while facing the burden of therapy. Setting or at least discussing the social or collective benefits of the treatment learned by a client could probably increase a client's involvement in therapy, especially for clients with an Eastern cultural background.

\section{References}

Antony, M. M. (2011). Recent advances in the treatment of anxiety disorders. Canadian Psychology/Psychologie Canadienne, 52(1), 1-9.

Arnault, D. S. \& Woo, S. (2018). Testing the influence of cultural determinants on help-seeking theory. American Journal of Orthopsychiatry, 88(6), 650-660.

Bernstein, D. A., Borkovec, T. D., \& Hazlett-Stevens, H. (2000). New directions in progressive relaxation training a guidebook for helping professionals. Westport, CT: Praeger.

Christensen, L. B., Johnson, B., \& Turner, L. A. (2015). Research methods, design, and analysis. Essex, England: Pearson.

Comer, R. J. \& Comer, J. S. (2018). Abnormal psychology. New York, NY: Macmillan Education.

Donegan, E. \& Dugas, M. J. (2012). Generalized anxiety disorder: A comparison of symptom changes in adults receiving cognitive-behavioral therapy or applied relaxation. Journal of Consulting and Clinical Psychology, 80(3), 490-496.

Fakultas Psikologi. (2017). Kumpulan Teknik Stabilisasi Emosi dan Resource Development and Installation (RDI). Kumpulan Tehnik Stabilisasi Emosi dan Resource Development and Installation (RDI). Depok.

Fenger, M., Mortensen, E., Poulsen, S., \& Lau, M. (2010). PW01-122 - No-shows, drop-outs and completers in psychotherapeutic treatment: demographic and clinical predictors in a large sample of non-psychotic patients. European Psychiatry, 25, 1538.

Goncalves, D. C. \& Byrne, G. J. (2012). Interventions for generalized anxiety disorder in older adults: Systematic review and meta-analysis. Journal of Anxiety Disorders, 26(1), 1-11.

Hall, J., Kellet, S., Berrios, R., Bains, M. K., \& Scott. (2016). Efficacy of Cognitive Behavioral Therapy for Generalized Anxiety Disorder in Older Adults: Systematic Review, Meta-Analysis, and Meta-Regression. The American Journal of Geriatric Psychiatry, 24(11) 1063-1073.

Hans, E. \& Hiller, W. (2013). A meta-analysis of nonrandomized effectiveness studies on outpatient cognitive behavioral therapy for adult anxiety disorders, Clinical Psychology Review, 33(8), 954-964.

Hans, E. \& Hiller, W. (2013). Effectiveness of and dropout from outpatient cognitive behavioral therapy for adult unipolar depression: A meta-analysis of nonrandomized effectiveness studies. Journal of Consulting and Clinical Psychology, 81(1), 75-88.

Hayes-Skelton, S. A., Roemer, L., \& Orsillo, S. M. (2013). A randomized clinical trial comparing an acceptancebased behavior therapy to applied relaxation for generalized anxiety disorder. Journal of Consulting and Clinical Psychology, 81(5), 761-773.

Hofstede, G. (2011). Dimensionalizing Cultures: The Hofstede Model in Context, Online Readings in Psychology and Culture, 2(1).

Issakidis, C. \& Andrews, G. (2004). Pretreatment attrition and dropout in an outpatient clinic for anxiety disorders. Acta Psychiatrica Scandinavica, 109(6), 426-433.

Lowman, R. L. \& Kilburg, R. R. (2011). Guidelines for case study submissions to Consulting Psychology Journal: Practice and Research. Consulting Psychology Journal: Practice and Research, 63(1), 1-5.

Roos, J. \& Weerbart, A. (2013). Therapist and relationship factors influencing dropout from individual psychotherapy: A literature review. Psychotherapy Research, 23(4), 394-418.

Ryder, A. G., Yang, J., Zhu, X., Yao, S., Yi, J., Heine, S. J., \& Bagby, R. M. (2008). The cultural shaping of 
depression: Somatic symptoms in China, psychological symptoms in North America? Journal of Abnormal Psychology, 117(2), 300-313.

Seligman, L. W. (2015). Theories of counseling and psychotherapy mycounselinglab without pearson etext: systems ... strategies, and skills. Place of publication not identified: Prentice Hall.

Siey, J. \& Chambless, D. L. (2008). Specificity of treatment effects: Cognitive therapy and relaxation for generalized anxiety and panic disorders': Correction., Journal of Consulting and Clinical Psychology, 76(5), iii-iii.

Swift, J. K. \& Greenberg, R. P. (2014). A treatment by disorder meta-analysis of dropout from psychotherapy. Journal of Psychotherapy Integration, 24(3), 193-207.

Soeswondo, S., Menaldi, A., \& Hanum, L. (2016). Stress, Manajemen Stress, dan Relaksasi Progresif. Depok: LPSP3.

Trull, T. J. \& Prinstein, M. J. (2013). Clinical psychology. Singapore: Cengage Learning Asia Pte Ltd.

Universitas Indonesia, "Buku Sambung Puskesmas Beji Minggu Praktik Institusi Profesi Klinis Dewasa." Puskesmas Beji, Depok, 03-Sep-2018. 